\title{
Attitudes of the Third-Year Clinical Anesthesiology Residents Toward an Independent Clinical Practice Rotation in COVID-19 Pandemic in
}

\section{Iran}

\author{
Ali Dabbagh (iD 1, ${ }^{*}$, Seyyedeh Narjes Ahmadizadeh ${ }^{2}$, Sogol Asgari ${ }^{2}$, Kamal Fani $^{2}$, Nilofar Massoudi (iD ${ }^{2}$, \\ Mohammadreza Moshari ${ }^{2}$, Parissa Sezari (iD) ${ }^{2}$, Sedigheh Shokrollahi ${ }^{2}$, Soodeh Tabashi ${ }^{2}$, Ardeshir \\ Tajbakhsh $^{2}$ and Maryam Vosoughian (iD ${ }^{2}$ \\ ${ }^{1}$ Anesthesiology Research Center, Shahid Beheshti University of Medical Sciences, Tehran, Iran \\ ${ }^{2}$ Anesthesiology Department, School of Medicine, Shahid Beheshti University of Medical Sciences, Tehran, Iran \\ "Corresponding author: Anesthesiology Research Center, Shahid Beheshti University of Medical Sciences, Tehran, Iran. Email: alidabbagh@yahoo.com
}

Received 2020 November 02; Revised 2020 December 07; Accepted 2020 December 07.

\begin{abstract}
Background: COVID-19 was a worldwide pandemic with international health emergencies and great challenges; health care personnel shortage and physician burnout is a potential major challenge that should be planned and managed; especially in those countries with a high COVID-19 occurrence.

Objectives: This study was designed to assess the attitudes of 3rd-year anesthesiology residents toward an independent one monthlength clinical care course for patients with COVID-19.

Methods: A closed self-administered questionnaire was developed to assess the attitudes of 3rd-year clinical anesthesiology residents. A self-administered closed questionnaire was developed. Cronbach's alpha was calculated to measure the reliability of the questionnaire; added with a factor analysis process.

Results: All 19 clinical anesthesiology residents took part in the study, with a 100\% response rate. Cronbach's alpha for the reliability of the questionnaire was 0.678 . The eigenvalue for 8 factors was equal to 1 ; however, further assessment led us to 7 factors.

Conclusions: This one-month period could improve the competencies of the 3rd year clinical anesthesiology residents based on their viewpoints. Since the COVID-19 pandemic is ongoing health and social problem worldwide, 3rd-year anesthesiology residents could help the health system to recover health care delivery faults regarding manpower; a promising point for crisis preparedness in the COVID-19 pandemic. Besides, there were many constructive results for the clinical anesthesiology residents regarding their training and clinical service delivery.
\end{abstract}

Keywords: COVID-19, Pandemic, Iran, Anesthesiology, Resident, Residency Training, Clinical Competency, Medical Education

\section{Background}

The novel coronavirus disease (COVID-19) due to severe acute respiratory coronavirus 2 (SARS-CoV-2) started in late 2019 with a global spread leading to a worldwide pandemic and an international health emergency $(1,2)$. Among many aspects of human life, this pandemic affected professional and emotional aspects of many people, including health care personnel; during this pandemic, there is always a potential chance that health care personnel shortage and physician burnout would happen; a major challenge that should be planned and managed (3). Iran was among the affected countries; facing a challenge due to the viral outbreak (4).

High-level intensive respiratory care quality, especially during the disease surge, is considered one of the bottlenecks in COVID-19 care; directly affecting COVID-19 attributed mortality rate (5-7). Anesthesiologists were considered one of the main cornerstones of critical care in patients with COVID-19 that many of them are affected by the disease or professional burnout leading to major concerns in delivering high-quality care with variable proposed solutions worldwide (3, 8-10).

More than five million people are under health care services by Shahid Beheshti University of Medical Sciences (SBMU), Tehran, Iran (11), including parts of the city and some of its suburbs. COVID-19 pandemic was a challenge mandating extraordinary care by Anesthesiology Department, SBMU. This included not only the academic medical 
centers but also the non-academic medical centers under the coverage of SBMU.

During the pandemic, SBMU had to seek the 3rd-year anesthesiology residents' services as independent care, mainly in the suburb hospitals. Though senior anesthesiology residents have to pass one-month independent care in Iran, this experience was different in some aspects; due to COVID-19-related factors $(8,10)$. Attitudes of healthcare providers could demonstrate many aspects of a decision and would improve the decision-makers in the health system $(12,13)$; in other words, if the impact of a medical education process is going to be assessed appropriately, the attitudes and feedback from trainee are of utmost importance (13-15).

\section{Objectives}

This study was designed to assess the attitudes of 3rdyear anesthesiology residents toward an independent onemonth-length clinical care course for patients with COVID19; to find their attitudes and find potential opportunities from this threat in a developing country faced with a major threat.

\section{Methods}

The study was approved by Institutional Review Board (code: IR.SBMU.RETECH.REC.1399.664) Research Ethics Committee, Shahid Beheshti University of Medical Sciences, Tehran, Iran; besides, the requirement for written informed consent was waived by the IRB due to the study method.

In a cross-sectional descriptive-analytic attitude assessment study, using a Delphi method, a closed selfadministered questionnaire was developed to assess the attitudes of 3rd-year clinical anesthesiology residents toward their professional experience during a one-month rotation serving patients with COVID-19 independently. To achieve the study sample size, a consensus method was used since the total target population was less than 20; i.e. all 3rd-year clinical anesthesiology residents were included.

After preparing the first draft of the questionnaire, the statements of the questionnaire were drafted and prepared on a 5-point Likert scale; then, the questionnaire was distributed among researchers and some other faculty members to increase face validity. The final questionnaire was an anonymous one with 29 closed answer questions added with an open-ended question about any other possible idea(s).

The study variables included the questionnaire items; which were quantitative ones; rated using the self-administered Likert scale. The age of the respondents and their gender were not included in the questionnaire to assure the anonymity of the replies since the sample size was 19. The results of the questionnaire responses were demonstrated and analyzed as a cumulative mean \pm standard deviation (SD) for each question. Furthermore, Cronbach's alpha was calculated to test the reliability of the questionnaire. Then, after calculating the eigenvalue for the questionnaire, the questions were categorized into seven factors using a factor analysis approach.

To support the residents, they had affiliated attending; available for telephone consult and support, in case they were faced with challenges in the decision-making process. In addition, the study was the result of a one-month rotation in SBMU; however, the residents were providing clinical care in different hospitals; though these hospitals had similar organizations and similar settings. Data entry and analysis were performed using SPSS (version 11.5; SPSS Inc, Chicago, IL, USA). To perform more advanced psychometric analysis, the eigenvalue and factor analysis were done.

\section{Results}

All 19 participants agreed to take part and respond to the questionnaire in an anonymous situation $(n=19)$. The reliability of the questionnaire was 0.678 ; i.e. Cronbach's alpha $=0.678$; for the whole questionnaire containing 29 closed statement questions; which suggested an appropriate level of reliability. The results of the 29 closed statement questions are demonstrated in Table 1 as the mean \pm SD. Factor analysis resulted in an eigenvalue $=1$ at 8 factors (Figure 1); however, after further analysis and based on the experiences of the research team, the factors were modified into seven factors indicated in Table 2 and Figure 1. Also, the full study questionnaire is summarized in Appendix 1 in Supplementary File.

\section{Discussion}

The current study demonstrated the role of an independent clinical rotation on different aspects of education and professional tasks of the 3rd year clinical anesthesiology residents based on their attitudes. This study showed that such a rotation, though maybe stressprovoking, could lead to some positive results and careerrelated improvements.

Iran is an eastern country with an ancient history of anesthesia (16). Throughout centuries, Iranian physicians have experienced a wide range of crisis management, including but not limited to earthquakes and war scenes $(17,18)$. However, the experiences gained in the COVID-19 


\section{Scree Plot}

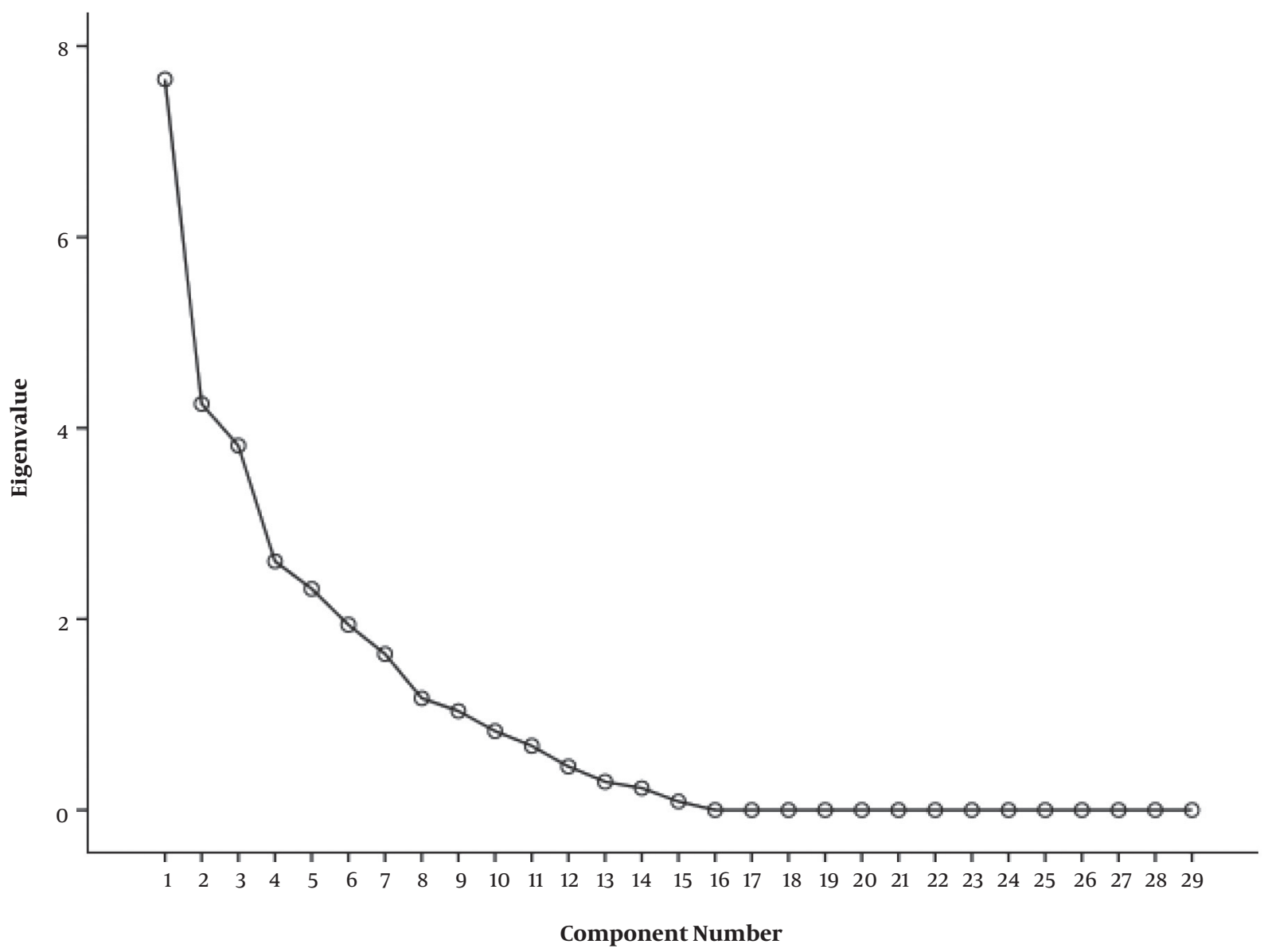

Figure 1. The calculated amount of the eigenvalue for 29 closed items of the questionnaire (the analysis demonstrated 8 factors equal an eigenvalue $=1$; however, based on the experiences of the researchers, 7 factors were determined to further analysis).

pandemic were somewhat different, especially considering the global and national situation $(4,19)$.

Stress-related challenges are among the leading factors affecting the performance of healthcare and are due to several different issues such as occupational and/or infectious hazards, faulty health care process during epidemics, financial-related issues, and many others $(3,10,20)$. Factor 1 demonstrated the stress-related items of the questionnaire; while nearly the majority of the anesthesiology residents had experienced the stress before going to the rotation. However, nearly all of them had been stress-free at the end of the rotation with varying degrees of stress relief throughout the one month; some were stress-free on the first day; while the others were stress-free in the middle of the last parts of the rotation. These findings support previous studies regarding the degree of stress during the COVID-19 pandemic in health care professionals $(3,10$, $20,21)$, demonstrating the rapid waning trend of the stress and burnout in the respondents' experiences, possibly due to a multitude of factors. One of them could be the role of motivational factors, independence in delivering clinical care, and self-regulated learning that has been discussed in the next paragraphs.

Stress-generating factors were mainly related to the effects of entering a new work setting, which had not been experienced before, the fear of occupational hazards for the resident and his/her family and the challenges in working independently and the potential lack of sufficient indirect supervision $(13,22)$; these could be dealt with to manage stress and improve the professional efficiency (factor 2). Possibly, there would be more contributing items related to stress generation $(10,23)$; however, the residents 


\begin{tabular}{ll}
\hline Table 1. The Results of 29 Closed Statement Questions as Mean \pm Standard Deviation \\
\hline Question Number & Mean \pm SD \\
\hline Q1 & $4.47 \pm 0.49$ \\
\hline Q2 & $2.01 \pm 1.11$ \\
\hline Q3 & $3.92 \pm 1.10$ \\
\hline Q4 & $2.95 \pm 1.11$ \\
\hline Q5 & $4.15 \pm 0.56$ \\
\hline Q6 & $4.53 \pm 0.46$ \\
\hline Q7 & $1.58 \pm 0.79$ \\
\hline Q8 & $3.05 \pm 1.17$ \\
\hline Q9 & $3.00 \pm 1.18$ \\
\hline Q10 & $1.26 \pm 1.28$ \\
\hline Q11 & $3.94 \pm 0.71$ \\
\hline Q12 & $3.78 \pm 0.71$ \\
\hline Q13 & $3.95 \pm 0.84$ \\
\hline Q14 & $3.88 \pm 0.82$ \\
\hline Q15 & $3.79 \pm 1.13$ \\
\hline Q16 & $2.12 \pm 0.48$ \\
\hline Q17 & $3.96 \pm 0.93$ \\
\hline Q18 & $3.74 \pm 0.93$ \\
\hline Q19 & $3.95 \pm 0.70$ \\
\hline Q20 & $4.05 \pm 0.82$ \\
\hline Q21 & $3.98 \pm 0.91$ \\
\hline Q22 & $3.67 \pm 0.97$ \\
\hline Q23 & $2.58 \pm 1.12$ \\
\hline Q24 & $4.00 \pm 0.57$ \\
\hline Q25 & $4.21 \pm 0.65$ \\
\hline Q & $2.95 \pm 0.97$ \\
\hline
\end{tabular}

did not mention any more items in the open question at the end of the survey.

Motivational factors were also important in the anesthesiology residents' professional career, not only in fulfilling their duties but also in motivating them to overcome the stresses (factor 3 ). In a prominently motivational item, the majority of the respondents declared their readiness to take part in a similar professional experience on any future occasion that there would be any necessity in the future (question 17). Besides, the motivational factors led to the improvement in core clinical competencies of the clinical anesthesiology residents, including but not limited to professionalism, practice-based learn-

\begin{tabular}{|c|c|c|}
\hline Factor Number & $\begin{array}{l}\text { Questions Categorized } \\
\text { in the Factor }\end{array}$ & $\begin{array}{l}\text { The Description of the } \\
\text { Factor }\end{array}$ \\
\hline Factor 1 & $1,2,7,8,9,10,18,21$ & $\begin{array}{l}\text { Stress-related challenges } \\
\text { during the course }\end{array}$ \\
\hline Factor 2 & $3,4,5,6,23$ & Stress-generating factors \\
\hline Factor 3 & $15,17,22,24$ & $\begin{array}{l}\text { Motivational factors to } \\
\text { overcome stress }\end{array}$ \\
\hline Factor 4 & $12,13,14,16,27,28$ & $\begin{array}{l}\text { Self-regulated learning in } \\
\text { OR and ICU care }\end{array}$ \\
\hline Factor 5 & $11,24,25$ & $\begin{array}{l}\text { Self-esteem and } \\
\text { satisfaction in clinical care }\end{array}$ \\
\hline Factor 6 & 19,20 & $\begin{array}{l}\text { Disaster and crisis } \\
\text { management }\end{array}$ \\
\hline Factor 7 & 29 & $\begin{array}{l}\text { Ethical aspects of clinical } \\
\text { care }\end{array}$ \\
\hline
\end{tabular}

ing, and improvement, interpersonal and communication skills, and leadership capacities, based on the Accreditation Council for Graduate Medical Education (ACGME) core competency model (24-26). The role of motivational factors and affective domains in improving ACGME core competencies has been previously confirmed; which is consistent with our findings (27-29).

Self-regulated learning is one of the most important strategies for the "life-long professional development of medical education"; mainly due to the very rapid development of medical knowledge $(30,31)$. This rapid development is possibly the most prominent in such events as the COVID-19 pandemic $(32,33)$. The results of factor 4 demonstrated the prominent role of this "one-month clinical rotation" on self-regulated learning of clinical anesthesiology residents regarding OR and ICU care (Tables 1 and 2). In similar studies, it has been demonstrated that creating goal-directed structures could improve the personal and professional goals of senior students, leading to improvements in their professional achievements, which were similar to our findings regarding the effects of this one-month rotation on goal-directed learning in an independent clinical experience (34-36).

Self-esteem and satisfaction in clinical care were strongly improved, though care of patients with COVID19 was considered a difficult clinical task based on the attitudes of the respondents to items in factor 5 .

Disaster and crisis management was another prominent aspect of the COVID-19 pandemic, which was addressed in this questionnaire (factor 6), and the respondents declared their positive views regarding their role in COVID-19 crisis management $(37,38)$. These positive feedbacks did not just pertain to the current situation; instead, could affect the clinical residents to be more experienced for similar episodes of disaster and crisis management 
based on their attitudes. However, mental preparedness in disaster and crisis management is one of the cornerstones of the whole process of disaster management (37).

Ethical aspects of clinical care were the last factor that included just one question in our analysis and demonstrated that the residents did feel happy if they were in the situation and place of the caregivers. This issue should be considered an ethical approach because neglecting such an issue may deteriorate the global clinical function of the caregivers $(39,40)$.

\subsection{Study Limitations}

All the residents were 3rd-year anesthesiology residents who were at the same level; however, we had not compared them in terms of quality of practice, ability to make rational decisions, performance under pressure, and stress management in critical situations before starting the one-month COVID-19 rotation. For stress assessment, we did not use a standard guideline, which is a study drawback. The study would result in better external validity with reasonable and extensile findings if we could perform the research in a larger group of residents; this is suggested to be considered in similar future studies.

\subsection{Conclusions}

This one-month period could improve the competencies of the 3rd year clinical anesthesiology residents based on their viewpoints. Since the COVID-19 pandemic is ongoing health and social problem worldwide, 3rd-year anesthesiology residents (possibly other senior anesthesiology residents) could help the health system to recover health care delivery faults regarding manpower; this is a promising point, especially regarding preparedness during disaster and crisis, particularly in COVID-19 pandemic. Also, there were many constructive results for the clinical anesthesiology residents regarding their training and clinical service delivery.

\section{Supplementary Material}

Supplementary material(s) is available here [To read supplementary materials, please refer to the journal website and open PDF/HTML].

\section{Footnotes}

Authors' Contribution: Ali Dabbagh did conceptualization, data collection; statistical analysis, funding acquisition; investigation; methodology; project administration, resources; software, supervision, Validation, visualization, writing the original draft, review and editing. Seyyedeh
Narjes Ahmadizadeh, Sogol Asgari, Kamal Fani, Mohammadreza Moshari, Parissa Sezari, and Sedigheh Shokrollahi did conceptualization; methodology, writing the original draft, review and editing. Nilofar Massoudi, Soudeh Tabashi, and Maryam Vosoughian did conceptualization, data collection, methodology, writing the original draft, review, and editing. Ardeshir Tajbakhsh did conceptualization; data collection; statistical analysis, methodology, software, validation; visualization, writing the original draft, review, and editing.

Conflict of Interests: None of the authors has any conflict of interest.

Ethical Approval: The ethical approval code was IR.SBMU.RETECH.REC.1399.664.

Funding/Support: This study was supported and granted by the Anesthesiology Research Center, Shahid Beheshti University of Medical Sciences, Tehran, Iran. The study research code is 24097.

Informed Consent: The requirement for written informed consent was waived by the IRB due to the study method.

\section{References}

1. Pergolizzi JJ, Magnusson P, LeQuang JA, Breve F, Paladini A, Rekatsina $\mathrm{M}$, et al. The Current Clinically Relevant Findings on COVID-19 Pandemic. Anesth Pain Med. 2020;10(2). e103819. doi:10.5812/aapm.103819. [PubMed: 32754437]. [PubMed Central: PMC7352949].

2. Darabi P, Kalo MB, Ali KM, Safari S, Yousefifard M, Hosseini M. COVID-19: Features, clinical course and concerns. J Cell Mol Anesth. 2020;5(2):102-13.

3. Sasangohar F, Jones SL, Masud FN, Vahidy FS, Kash BA. Provider Burnout and Fatigue During the COVID-19 Pandemic: Lessons Learned From a High-Volume Intensive Care Unit. Anesth Analg. 2020;131(1):106-11. doi: 10.1213/ANE.0000000000004866. [PubMed: 32282389]. [PubMed Central: PMC7173087].

4. Takian A, Raoofi A, Kazempour-Ardebili S. COVID-19 battle during the toughest sanctions against Iran. Lancet. 2020;395(10229):10356. doi: 10.1016/S0140-6736(20)30668-1. [PubMed: 32199073]. [PubMed Central: PMC7138170].

5. Huang C, Wang Y, Li X, Ren L, Zhao J, Hu Y, et al. Clinical features of patients infected with 2019 novel coronavirus in Wuhan, China. Lancet. 2020;395(10223):497-506. doi: 10.1016/S0140-6736(20)30183-5. [PubMed: 31986264]. [PubMed Central: PMC7159299].

6. Meng L, Qiu H, Wan L, Ai Y, Xue Z, Guo Q, et al. Intubation and Ventilation amid the COVID-19 Outbreak: Wuhan's Experience. Anesthesiology. 2020;132(6):1317-32. doi: 10.1097/ALN.0000000000003296. [PubMed: 32195705]. [PubMed Central: PMC7155908].

7. Mahmoodpoor A, Shadvar K, Ghamari AA, Mohammadzadeh Lameh M, Asghari Ardebili R, Hamidi M, et al. Management of Critically Ill Patients with COVID-19: What We Learned and What We Do. Anesth Pain Med. 2020;10(3). e104900. doi: 10.5812/aapm.104900. [PubMed: 32944565]. [PubMed Central: PMC7472789].

8. Hassanian-Moghaddam H, Zamani N, Kolahi AA. COVID-19 pandemic, healthcare providers' contamination and death: an international view. Crit Care. 2020;24(1):208. doi: 10.1186/s13054-020-02938-y. [PubMed: 32384910]. [PubMed Central: PMC7209975]. 
9. Janbabai G, Razavi S, Dabbagh A. How to manage perioperative patient flow during COVID-19 pandemic: a narrative review. J Cell Mol Anesth. 2020;5(1):47-56.

10. Ali H, Eissa S, Magdy H, Khashba M. Dexmedetomidine as an Additive to Local Anesthesia for Decreasing Intraocular Pressure in Glaucoma Surgery: A Randomized Trial. Anesth Pain Med. 2020;10(3). e100673. doi: 10.5812/aapm.100673. [PubMed: 32944557]. [PubMed Central: PMC7472791].

11. Sezari P, Tajbakhsh A, Massoudi N, Arhami Dolatabadi A, Tabashi S, Sayyadi S, et al. Evaluation of One-Day Multiple-Choice Question Workshop for Anesthesiology Faculty Members. Anesth Pain Med. 2020;In Press(In Press). doi: 10.5812/aapm.111607.

12. Schwed AC, Lee SL, Salcedo ES, Reeves ME, Inaba K, Sidwell RA, et al. Association of General Surgery Resident Remediation and Program Director Attitudes With Resident Attrition. JAMA Surg. 2017;152(12):113440. doi: 10.1001/jamasurg.2017.2656. [PubMed: 28813585]. [PubMed Central: PMC5831434].

13. Dabbagh A, Sezari P, Tabashi S, Tajbakhsh A, Massoudi N, Vosoghian M, et al. Attitudes of Anesthesiology Residents Toward a Small Group Blended Learning Class. Anesth Pain Med. 2020;10(3). e103148. doi: 10.5812/aapm.103148.

14. Oldham J. Attitude. J Psychiatr Pract. 2012;18(4):229. doi: 10.1097/01.pra.0000416013.15097.21. [PubMed: 22805897].

15. Hepler J, Albarracin D. Liking More Means Doing More: Dispositional Attitudes Predict Patterns of General Action. Soc Psychol (Gott). 2014;45(5):391-8. doi: 10.1027/1864-9335/a000198. [PubMed: 29375723]. [PubMed Central: PMC5783546].

16. Dabbagh A, Rajaei S, Golzari SE. History of anesthesia and pain in old Iranian texts. Anesth Pain Med. 2014;4(3). e15363. doi: 10.5812/aapm.15363. [PubMed: 25237631]. [PubMed Central: PMC4164984].

17. Saberian P, Kolivand PH, Hasani-Sharamin P, Dadashi F, Farhoud AR. Iranian Emergency Medical Service Response in Disaster; Report of three Earthquakes. Adv J Emerg Med. 2019;3(2). e13. doi: 10.22114/AJEM.v0i0.121. [PubMed: 31172124]. [PubMed Central: PMC6548112].

18. Rahimi-Movaghar V, Jazayeri SB, Alimi M, Abbassioun K, Amirjamshidi A. Lessons learned from war: a comprehensive review of the published experiences of the Iranian neurosurgeons during the Iraq-Iran conflict and review of the related literature. World Neurosurg. 2013;79(2):346-58. doi: 10.1016/j.wneu.2012.08.004. [PubMed: 22929108].

19. van Dijk JF, Schuurmans MJ, Alblas EE, Kalkman CJ, van Wijck AJ. Postoperative pain: knowledge and beliefs of patients and nurses J Clin Nurs. 2017;26(21-22):3500-10. doi: 10.1111/jocn.13714. [PubMed: 28042880].

20. Spoorthy MS, Pratapa SK, Mahant S. Mental health problems faced by healthcare workers due to the COVID-19 pandemic-A review. Asian J Psychiatr. 2020;51:102119. doi: 10.1016/j.ajp.2020.102119. [PubMed: 32339895]. [PubMed Central: PMC7175897].

21. Pappa S, Ntella V, Giannakas T, Giannakoulis VG, Papoutsi E, Katsaounou P. Prevalence of depression, anxiety, and insomnia among healthcare workers during the COVID-19 pandemic: A systematic review and meta-analysis. Brain Behav Immun. 2020;88:901-7. doi: 10.1016/j.bbi.2020.05.026. [PubMed: 32437915]. [PubMed Central: PMC7206431].

22. Dabbagh A, Abtahi D, Aghamohammadi H, Ahmadizadeh SN, Ardehali SH. Relationship Between "Simulated Patient Scenarios and Role-Playing" Method and OSCE Performance in Senior Anesthesiology Residents: A Correlation Assessment Study. Anesth Pain Med. 2020;10(5). doi: 10.5812/aapm.106640.

23. Dabbagh A, Elyassi H, Sabouri AS, Vahidshahi K; Ziaee. AnesthesiologyDepartment. The Role of Integrative Educational Intervention Package (Monthly ITE, Mentoring, Mocked OSCE) in Improving Successfulness for Anesthesiology Residents in the National Board Exam. Anesth
Pain Med.2020;10(2). e98566. doi: 10.5812/aapm.98566.

24. Kimatian SJ, Martin DE, Marine R, Mets B. A Model for Developing ACGME Competencies in an Academic Anesthesiology Department. Educ Perioper Med. 2007;9(1). E042. [PubMed: 27175435]. [PubMed Central: PMC4803411].

25. Rajaei S, Dabbagh A. Interdisciplinary approach and anesthesiology: is there any role? J Cell Mol Anesth. 2016;1(3):129-33.

26. Rajaei S, Dabbagh AT. he Role of Education in Personalized Anesthesiology, Pain and Perioperative Medicine. In: Dabbagh A. (eds) Personalized Medicine in Anesthesia, Pain and Perioperative Medicine. Springer, Cham; 2021. doi: 10.1007/978-3-030-53525-4.

27. Yanofsky SD, Nyquist JG. Using the Affective Domain to Enhance Teaching of the ACGME Competencies in Anesthesiology Training. Educ Perioper Med.2010;12(1). E055. [PubMed: 27175387]. [PubMed Central: PMC4719552].

28. Rinehart J, Seong J, Alem N, Andreatta R, Derhovanesian J, Smith C, et al. Anesthesiology Residency Curriculum and Implementation of a Perioperative Surgical Home Curriculum: A Survey Study. J Educ Perioper Med. 2017;19(3). E609. [PubMed: 29600254]. [PubMed Central: PMC5868368].

29. Rutz M, Turner J, Pettit K, Palmer MM, Perkins A, Cooper DD. Factors that Contribute to Resident Teaching Effectiveness. Cureus. 2019;11(3) e4290. doi: 10.7759/cureus.4290. [PubMed: 31183271]. [PubMed Central: PMC6538232].

30. van Houten-Schat MA, Berkhout JJ, van Dijk N, Endedijk MD, Jaarsma ADC, Diemers AD. Self-regulated learning in the clinical context: a systematic review. Med Educ. 2018;52(10):1008-15. doi: 10.1111/medu.13615. [PubMed: 29943415]. [PubMed Central: PMC6175376].

31. Sezari P, Dabbagh A. Personalized medicine: the paradigm shift in medicine mandating lifelong learning.J Cell Mol Anesth. 2019;4(2):312.

32. Lurie N, Saville M, Hatchett R, Halton J. Developing Covid-19 Vaccines at Pandemic Speed. NEngl JMed.2020;382(21):1969-73. doi:10.1056/NEJMp2005630. [PubMed: 32227757].

33. Li H, Liu Z, Ge J. Scientific research progress of COVID-19/SARS CoV-2 in the first five months. J Cell Mol Med. 2020;24(12):655870. doi: 10.1111/jcmm.15364. [PubMed: 32320516]. [PubMed Central: PMC7264656].

34. O'Brien BC, Niehaus B, Teherani A, Young IQ. Residents' perspectives on the final year of medical school. Int J Med Educ. 2012;3:151-8. doi: 10.5116/ijme.5019.6b01. [PubMed: 28029642]. [PubMed Central: PMC4205525].

35. Saddawi-Konefka D, Baker K, Guarino A, Burns SM, Oettingen G, Gollwitzer PM, et al. Changing Resident Physician Studying Behaviors: A Randomized, Comparative Effectiveness Trial of Goal Setting Versus Use of WOOP. J Grad Med Educ. 2017;9(4):451-7. doi:10.4300/JGME-D-1600703.1. [PubMed: 28824757]. [PubMed Central: PMC5559239].

36. Fadaizadeh L, Vosoughian M, Shajareh E, Dabbagh A, Heydari G. Is teleeducation a proper substitute for regular method to train anesthesiology residents? J Cell Mol Anesth. 2019;4(1):15-9.

37. Andreae MH, Dudak A, Cherian V, Dhar P, Dalal PG, Po W, et al. Healthcare simulation to prepare for the COVID-19 pandemic. J Clin Anesth.2020;66:109928. doi:10.1016/j.jclinane.2020.109928. [PubMed: 32485542]. [PubMed Central: PMC7250760].

38. Cheung EHL, Chan TCW, Wong JWM, Law MS. Sustainable response to the COVID-19 pandemic in the operating theatre: need for more than just personal protective equipment. Br J Anaesth. 2020;125(2):e242-4 doi: 10.1016/j.bja.2020.04.002. [PubMed: 32312569]. [PubMed Central: PMC7151450].

39. Parkin T, de Looy A, Farrand P. Greater professional empathy leads to higher agreement about decisions made in the consultation. Patient Educ Couns. 2014;96(2):144-50. doi: 10.1016/j.pec.2014.04.019. [PubMed: 24857331].

40. Davoodvand S, Abbaszadeh A, Ahmadi F. Patient advocacy from the clinical nurses' viewpoint: a qualitative study.J Med Ethics History Med. 2016;9. 